\title{
MASTERPLANNER: A CENTRAL UTILITY PLANT DESIGN AND OPTIMIZATION TOOL
}

\author{
Pouya Rezazadeh Kalehbasti ${ }^{1}, \mathrm{Te} \mathrm{Qi}^{2}$ \\ ${ }^{1}$ Stanford University, Stanford, CA \\ ${ }^{2}$ Atelier Ten USA LLC., San Francisco, CA
}

\begin{abstract}
This paper presents a web-based software for designing optimal central utility plants. This tool can receive userdefined load profiles or generate typical load profiles based on user-specified combination and areas of 16 reference building types. The software then solves a linear-programming optimization comprising 8760 sets of equations and constraints to design central plant configurations with minimal first cost, operating cost, life-cycle cost, energy use, or marginal carbon emissions. The tool also calculates simultaneous heating and cooling loads to evaluate using heat-recovery chillers, and it can design both hot and cold thermal energy storage as well as water-side economizers.
\end{abstract}

\section{NOMENCLATURE}

$T_{\text {cooling }} / T_{\text {heating }}=$ number of types of cooling/heating equipment

$\mathrm{C}_{\mathrm{i}}=$ Hourly Cooling Consumed or Generated [kW]

$\mathrm{H}_{\mathrm{i}}=$ Hourly Heating Consumed or Generated [kW]

$\mathrm{E}=$ Electricity

$\mathrm{E}_{\mathrm{i}}=$ Hourly Electricity Consumed or Generated $[\mathrm{kW}]$

$\mathrm{G}=$ Natural Gas

$\mathrm{G}_{\mathrm{i}}=$ Hourly Natural Gas Consumed or Generated [kW]

$\mathrm{P}_{\mathrm{i}}=$ Hourly Price $[\$ / \mathrm{kW}]$

h or $\mathrm{i}=$ Hour (range: $[1,8760])$

$\mathrm{m}=$ Month (range: $[1,12])$

$\mathrm{t}=$ Integer representing each cooling or heating technology type (HRC, ASHP, Chiller, etc.)

\section{ASHP = Air-Sourced Heat Pump}

tier $=$ denotes off-peak, mid-peak, peak, and normal periods during each month per the electricity tariff structure

cap = capacity $[\mathrm{kWh}]$

$C A P E X_{t}=$ Capital Expense for equipment of type $t$ [\$]

$\mathrm{COP}=$ Coefficient of Performance

$\mathrm{EC}=$ Electric Chiller

Grid $_{\text {Emission }_{h}}^{E}=$ Hourly emission of electric grid $[\mathrm{kg}$ $\left.\mathrm{CO}_{2 \_ \text {eq }} / \mathrm{kW}\right]$
Grid $_{\text {Emission }_{h}}^{G}=$ Hourly emission of natural gas grid $[\mathrm{kg}$ $\left.\mathrm{CO}_{2 \_ \text {eq }} / \mathrm{kW}\right]$

$\mathrm{HRC}=$ Heat-Recovery Chiller

NPV $=$ Net Present Value [\$]

TES = Thermal Energy Storage

SOC $=$ State of Charge [kWh]

WSE $=$ Water-Side Economizer

$\eta_{\text {CAPEX }}=$ User-defined factor for converting equipment cost into initial capital expenses

$\eta_{O P E X}=$ User-defined factor for converting fuel expenses into operational expenses

\section{INTRODUCTION}

For master planning projects, one of the key questions for the design team at the conceptual design phase is whether a district energy plant is needed and what the best combination of technologies (heat recovery chiller, thermal energy storage, air source heat pump, etc.) are to use for achieving the project goals, e.g. minimizing source energy, life cycle cost, or operational carbon emissions. Some tools are designed to provide limited insights on selecting a set of thermal/electrical supply technologies at a high level, e.g. SAM (Blair et al. 2014), PVWatts (Dobos 2014), and ReOpt (Simpkins et al. 2014), also some frameworks have been developed for this purpose as studied by Snoek et al. (2002), Rezaie and Rosen (2012), and Best et al. (2019). However, these tools and frameworks mostly act as recommendation systems with high-level optimization capabilities: they lack an integrated approach to detailed design of both cooling and heating supply equipment. Further, the optimization done in these tools mostly concerns minimizing life-cycle cost of equipment. Hence, currently no tool in the market can easily answer the mentioned question for the design team.

This paper introduces a design and optimization tool for central utility plants (CUP) incorporating cooling and heating supply systems as well as thermal energy storage. This tool has 3 pre-defined central plant configurations: The first one is a business as usual "electric-chiller + gas-boiler" configuration, the second one is "heat-recovery-chiller + electric-chiller + gasboiler", and the third one is an all-electric "heat recovery 
chiller + electric-chiller + air-sourced heat pump" to represent the all-electric design as a crucial approach to creating low-carbon built environments. Thermal energy storage can be included on top of all the 3 central plant options. Users can choose any of the configurations or all of them to be analyzed and optimized, and then compare the performance of the selected scenarios with a distributed (building by building) heating/cooling system.

Figure 1 presents a screenshot of the analysis panel in the tool to demonstrate the type of analysis the tool could accomplish. Figure 2 shows a sample output graph from the software showing the heating/cooling load profile of a particular site as well as the overlap between the thermal loads (indicating the feasibility of using heatrecovery chillers). Figure 3 demonstrates a sample output graph showing the optimal operation of the CUP with hourly supply and demand profiles of a sample scenario. Appendix shows a sample screenshot of part of the results as viewed in MasterPlanner.

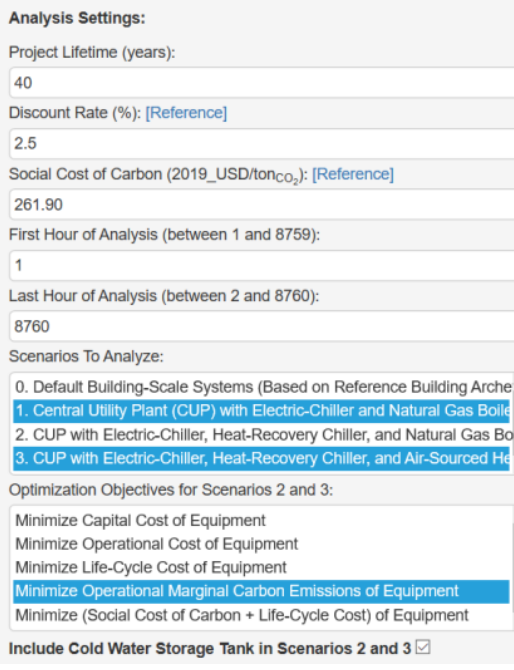

Figure 1. A screenshot of the input panel in MasterPlanner

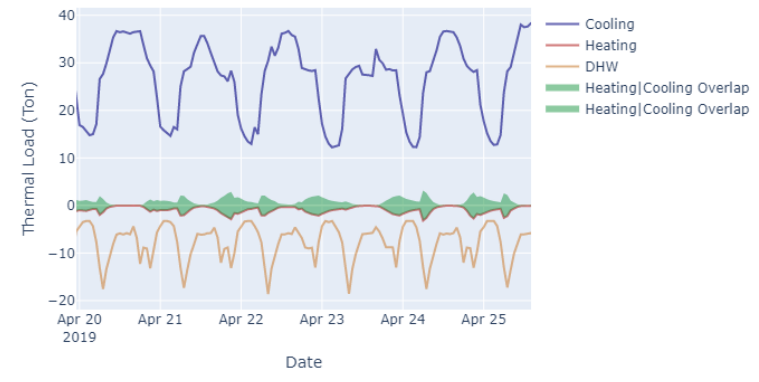

Figure 2. Sample demand plot for hourly heating, cooling, and domestic hot-water

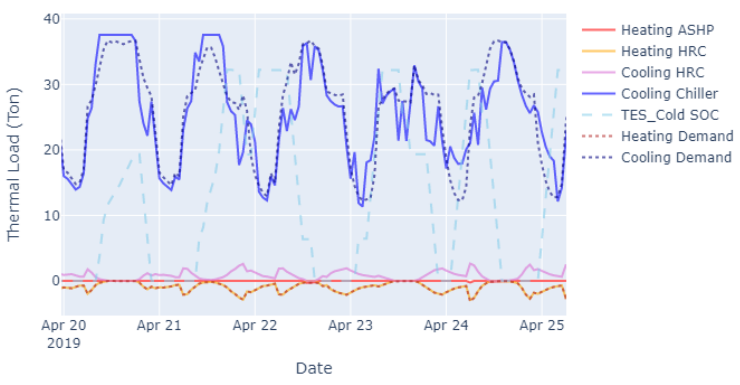

Figure 3. Sample optimized central utility plant supply and demand profiles for a sample case study

The introduced tool creates the energy demands imposed on the CUP based on the configurations of the development. According to these demands, the program then calculates the optimal capacities, optimal hourly generation, and lifecycle performance metrics (e.g. energy use intensity, marginal carbon emissions, lifecycle cost) of the supply equipment. The inputs to the toolbox consist of the following:

1. Location: location of the development used for obtaining the hourly weather conditions and regional natural gas price

2. Development Compactness: compactness of the development (low, medium, high) which determines the distribution losses

3. Demands: cooling, heating, domestic hot-water, and electricity demands synthesized based on the areas of building archetypes, or input directly by the user

4. Analysis Settings: four pre-defined supply side configurations (one distributed option and three central plant options), specifications including the project lifetime, discount rate, social cost of carbon, first hour and last hour of analysis, scenarios to analyze, and configurations of the scenarios 
5. Utility Rate Structure: Electric and natural gas utility rates and schedule

An innovative feature of this tool is its using hourly marginal carbon emission factors to optimize the system capacity and operation instead of using average carbon emissions (which is common practice in industry). The following section explains this concept in more detail.

\section{Marginal Carbon Emissions}

"Adding an additional unit of electrical demand or supply to a power grid at a specific place and time changes the load on the power plants that produce electricity at that time, otherwise known as the marginal power plant(s). The specific properties of the marginal power plant(s), including efficiency and fuel type, determine the magnitude of the emissions of that plant." (DiStefano and Richardson 2019) Variations in demand have significantly different impacts on the changes in emissions of the grid due to the temporal and spatial variety of marginal plants. Figure 4 shows a schematic diagram of the changes in grid conditions and emissions throughout the day. The figure shows that the cleanest time of the day is when renewable generation surpasses the demand on the grid, and added loads have low or zero GHG emissions as renewables are curtailed at this period.

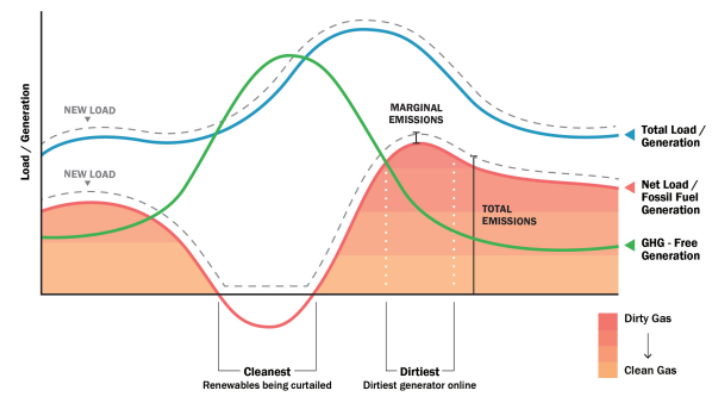

Figure 4. Schematic plot of daily changes in grid emissions vs the total and net loads. Taken from and courtesy of DiStefano and Richardson (2019)

The proposed tool uses the carbon emissions associated with marginal plants to evaluate the environmental performance of the system and optimize the equipment, as these plants respond to load variations and are associated with the real grid emissions.

\section{METHODOLOGY}

MasterPlanner calculates the optimal capacities and hourly operation of the supply equipment based on the demands on the central plant. These hourly cooling, heating, and hot-water demands can be either input directly by the user, or be synthesized using the typical demands from 16 different building prototypes (Deru et al. 2011). The user inputs the areas of each building type existing in a development to enable the software to synthesize the loads in the second method. For operational cost calculations, the software can use a default hourly utility rate structure or accept user-defined tariffs.

The software is developed using Flask (Grinberg 2018) web-development library in Python programming language (Van Rossum 2007). The back-end calculations are done mainly using Pyomo (Hart et al. 2017) for optimization, Pandas (McKinney 2011) for data handling, and Plotly (Sievert et al. 2017) for visualizations. The front-end user-interface is created using HTML5 and JavaScript. The following section details the optimization problem solved by MasterPlanner to calculate the optimal capacities and hourly operation of the supply equipment.

\section{Optimization Problem}

\section{Decision Variables:}

The decision variables used in this optimization problem are listed below.

- $\quad C_{h}^{t}, C_{\text {cap }}^{t} \mid t \in\left[1, T_{\text {cooling }}\right]$ and $h \in[1,8760]:$ Hourly cooling generation and capacities of all the $T_{\text {cooling }}$ types of cooling equipment, in $\mathrm{kW}$

- $\quad H_{h}^{t}, H_{\text {cap }}^{t} \mid t \in\left[1, T_{\text {heating }}\right]$ and $h \in[1,8760]:$ Hourly heating generation and capacities of all the $T_{\text {heating }}$ types of heating equipment, in $\mathrm{kW}$

- $\quad C_{h, \text { in }}^{T E S}, C_{h, \text { out }}^{T E S}, C_{h, S O C}^{T E S} \mid h \in[1,8760]:$ Hourly input (in $\mathrm{kW}$ ), output (in $\mathrm{kW}$ ), and state-of-charge (in $\mathrm{kW}$-hr) of the cold-water storage tanks

- $\quad H_{h, i n}^{T E S}, H_{h, o u t}^{T E S}, H_{h, S O C}^{T E S} \mid h \in[1,8760]:$ Hourly input (in $\mathrm{kW}$ ), output (in $\mathrm{kW}$ ), and state-of-charge (in kW-hr) of the hot-water storage tanks

- $\quad E_{m, t i e r}^{\text {peak }} \mid m \in[1,12]$ and tier $\in$ $\{$ peak, midpeak, offpeak,total\}: Monthly peak electricity demand during each usage tier, in $\mathrm{kW}$

\section{Objective Function:}

The optimization problem solved by the tool can have three different objective functions: (i) Equation (1) defines the first type objective function, i.e. lifecycle cost of equipment, (ii) Equation (2) defines the second type objective function, i.e. operational marginal carbon emissions, and (iii) Equation (3) introduces the combined objective function of lifecycle cost and social cost of carbon. The tool is also capable of designing the 
equipment for minimal first costs or operational costs alone.

$$
\begin{aligned}
& \min N P V\left(\sum_{h=1}^{8760}\left(\sum_{t=1}^{T_{\text {cooling }}}\left(E_{h}^{t}\right) * P_{h}^{E}\right)+\right. \\
& \sum_{m=1}^{12}\left(\sum_{\text {tier }}\left(E_{m, \text { tier }}^{\text {peak }} * P_{m, \text { tier }}^{E}\right)\right)+ \\
& \left.\sum_{h=1}^{8760}\left(\sum_{t=1}^{T_{\text {heating }}}\left(G_{h}^{t}\right) * P_{h}^{G}\right)\right) * \eta_{\mathrm{OPEX}}+ \\
& \sum_{t=1}^{T_{\text {cooling }}+T_{\text {heating }}}\left(C A P E X_{t}\right) * \eta_{\text {CAPEX }} \\
& \min \left(\sum_{h=1}^{8760}\left(\sum_{t=1}^{T_{\text {cooling }}}\left(E_{h}^{t}\right) * \text { Grid }_{\text {Emission }}{ }_{h}^{E}\right)+\right. \\
& \left.\sum_{h=1}^{8760}\left(\sum_{t=1}^{T_{\text {heating }}}\left(G_{h}^{t}\right) * \text { Grid }_{\text {Emission }}{ }_{h}\right)\right) \\
& \min (\text { LCC }+ \text { OE } * S C C)
\end{aligned}
$$

where LCC is the lifecycle cost objective (defined by Equation (1)), $\mathrm{OE}$ is the operational emissions (defined by Equation (2)), and SCC is the social cost of carbon $\left[\$ / \mathrm{kg}_{\mathrm{CO} 2}\right]$ as defined by Tol (2008) and adopted by EPA (EPA 2016).

\section{Constraints:}

- Constraints on capacities:

$C_{h}^{t} \leq C_{\text {cap }}^{t} \mid$ for $t \in\left[1, T_{\text {cooling }}\right]$ and $h \in[1,8760]$

$H_{h}^{t} \leq H_{\text {cap }}^{t} \mid$ for $t \in\left[1, T_{\text {heating }}\right]$ and $h \in[1,8760]$

- Constraint on electricity usage:

$$
E_{i}^{t}=\frac{c_{i}^{t}}{\operatorname{CoP}_{i}^{t}} \mid \text { for } i \in[1,8760]
$$

where COP is a function of the hourly temperature except for HRC which is assumed to have a constant COP

- Constraint on natural gas usage:

$$
G_{i}^{t}=\frac{H_{i}^{t}}{\operatorname{COP}^{t}} \mid \text { for } i \in[1,8760]
$$

- Constraint on demand and supply:

$$
\begin{aligned}
& C_{i}^{\text {Demand }} *\left(1-\eta_{W S E_{i}}\right)+C_{i, \text { in }}^{T E S}= \\
& \sum_{t=1}^{T_{\text {cooling }}}\left(C_{i}^{t}\right)+C_{i, \text { out }}^{T E S} \mid \text { for } i \in[1,8760]
\end{aligned}
$$

here, $\eta_{W S E_{i}}$ is the hourly coefficient of WSE which denotes how much of the cooling load it can satisfy.

$$
\begin{aligned}
& H_{i}^{\text {Demand }}+H_{i, \text { in }}^{T E S}=\sum_{t=1}^{T_{\text {heating }}}\left(H_{i}^{t}\right)+ \\
& H_{i, \text { out }}^{T E S} \mid \text { for } i \in[1,8760]
\end{aligned}
$$

- Constraints on operation of TES:
- Cold water storage tank (for $i \in[1,8760]$ ):

$$
\begin{aligned}
& C_{i, S O C}^{T E S} \leq C_{\text {cap }}^{T E S} \\
& C_{i, \text { out }}^{T E S} \leq C_{i, S O C}^{T E S} \\
& C_{i, \text { in }}^{T E S} \leq C_{i, \text { max }_{\text {in }}}^{T E S} \\
& C_{i, \text { out }}^{T E S} \leq C_{i, \max _{\text {mout }} \text { out }}^{T E S} \\
& C_{S O C_{\text {min }}}^{T E C_{i, S O C}} \leq C_{S O C_{\text {cap }}}^{T E S} \\
& C_{i, S O C}^{T E S}=C_{i-1, S O C}^{T E S}+C_{i-1, \text { in }}^{T E S}-C_{i-1, \text { out }}^{T E S} \\
& C_{1, S O C}^{T E S}=C_{S O C_{\text {init }}}^{T E S}
\end{aligned}
$$

○ Hot water storage tank (for $i \in[1,8760]$ ):

$$
\begin{aligned}
& H_{i, \text { SOC }}^{T E S} \leq H_{\text {cap }}^{T E S} \\
& H_{i, \text { out }}^{T E S} \leq H_{i, \text { SOC }}^{T E S} \\
& H_{i, \text { in }}^{T E S} \leq H_{i, \text { max }_{\text {in }}}^{T E S} \\
& H_{i, \text { out }}^{T E S} \leq H_{i, \text { max }_{\text {out }}}^{T E S} \\
& H_{S O C_{\text {min }}}^{T E H_{i, S O C}} \leq H_{\text {SOC }_{\text {cap }}}^{T E S} \\
& H_{i, \text { SOC }}^{T E S}=H_{i-1, S O C}^{T E S}+H_{i-1, \text { in }}^{T E S}-H_{i-1, \text { out }}^{T E S} \\
& H_{1, \text { SOC }}^{T E S}=H_{\text {SOC }}^{T E S \text { init }}
\end{aligned}
$$

\section{CASE STUDY}

This section presents a case study on assessing the feasibility of a central utility plant (CUP) and chilled water storage tank (TES) for a new campus located at Darwin, Australia. Commercial Reference Buildings modeled by US National Renewable Energy Laboratory (NREL) (Deru et al. 2011) were used to simulate the building mix in this project.

For this analysis, a central utility plant (with and without TES) was analyzed and compared with a building level thermal supply system over 30 years of lifetime with a $3 \%$ discount rate. A distribution loss of 5\% was applied to the loads which were supplied by the central utility plant.

\section{Thermal Equipment}

The building-level thermal supply technologies included natural-gas boilers and electric heaters for space-heating, electric coolers for cooling, and natural-gas hot-water boilers. Specifications of the cooling and heating equipment are listed below:

Electric Chiller (Atelier Ten, n.d.):

$$
\text { - Unit Cost (\$/ton): } 1460
$$

Heat-Recovery Chiller (Atelier Ten, n.d.):

- Unit Cost (\$/ton): 2400

- COP: 3

Cold Water Storage Tank:

- Unit Cost (\$/ton) (Tehrani et al. 2017):77.46

- Initial Storage (Btu): 0 
- $\quad$ Minimum Storage (Btu): 0

- Maximum Inflow in 1 hour (fraction of TES capacity): 0.2

- Maximum Outflow in 1 hour (fraction of TES capacity): 0.2

- Round-Trip Efficiency (fraction) (USGBC 2010): 0.95

- Hourly Energy Loss (fraction) (Sioshansi and Denholm 2010): 0.00031

Building-level Electric Heater:

- Unit Cost (\$/ton) (Build.com n.d.): 418.52

Air-Sourced Heat Pump:

- Unit Cost (\$/ton) (HomeAdvisor n.d.): 2200

Building-level Natural Gas Boiler:

- Unit Cost (\$/ton) (The Home Depot n.d.): 296.73

- Efficiency (fraction): 0.8

\section{Utilities}

Hourly marginal grid emissions for Delaware state, US, were used from Watttime's database (Siler-Evans, Azevedo, and Morgan 2012) for calculating the operational carbon emissions reported for each scenario. The electricity in the mentioned grid is generated by $87 \%$ natural-gas-powered generators and 5\% coal-powered generators (US EIA 2018) which was considered the closest among the US grids to the $\sim 60 \%$ natural-gas and $\sim 40 \%$ oil-powered generation (Ball et al. 2018) in Northern Territory, Australia. Electric utility tariffs were adopted from Jacana Energy (Jacana Energy 2019) with a peak-time (6am-6pm) energy charge of 0.2145 AUD/kWh, and an off-peak time energy charge of 0.1705 AUD/kWh.

The price of natural gas for building-level systems was assumed (US EIA n.d.) $16.46 \mathrm{AUD} / 1000 \mathrm{ft}^{3}$, and the natural gas $\mathrm{CO} 2$ emission factor was assumed (US EPA 2018) $53.06 \mathrm{~kg} / \mathrm{MMBtu}$.

\section{Weather Inputs}

Weather inputs were extracted from WMO Region 5 dataset." "Weather Data by Location | EnergyPlus" 2019). Figure 5 shows the histogram of hourly drybulb and wetbulb temperatures over the year for Darwin, Australia.

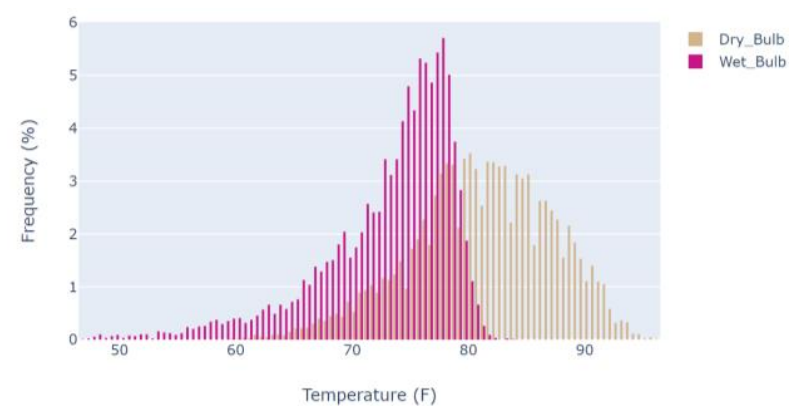

Figure 5. Histogram of annual hourly drybulb/wetbulb temperature for Darwin, Australia

\section{Programs}

The central plant was designed to supply the cooling, heating, and domestic hot-water demand from $31,000 \mathrm{~m}^{2}$ of university space (modeled as $26,000 \mathrm{~m}^{2}$ of Secondary School and $5,000 \mathrm{~m}^{2}$ of Large Office from NREL's Commercial Reference Building archetypes), 35,000 $\mathrm{m}^{2}$ of student residence (modeled as Large Hotel building archetype), $6,000 \mathrm{~m}^{2}$ of commercial office (modeled as Large Office building archetype), and $3,000 \mathrm{~m}^{2}$ of amenities (modeled as Out-Patient building archetype).

\section{Results and Analysis}

Table 1 shows the peak and average cooling, heating, domestic-hot water, and electric loads synthesized by the toolbox and imposed on a central utility plant, i.e. including distribution losses.

Table 1. Peak and average cooling, heating, DHW, and electricity demands for the case study

\begin{tabular}{|c|c|c|c|}
\hline \multicolumn{4}{|c|}{ Peak Demands } \\
\hline \multicolumn{3}{|c|}{ Thermal Demands } & \multirow{2}{*}{$\begin{array}{l}\text { Electrical Demand } \\
(\mathrm{kW})\end{array}$} \\
\hline $\begin{array}{l}\text { Cooling } \\
\text { (Ton) }\end{array}$ & $\begin{array}{l}\text { Heating } \\
\text { (kBtu/hr) }\end{array}$ & $\begin{array}{l}\text { DHW } \\
\text { (kBtu/hr) }\end{array}$ & \\
\hline 1251.2 & 4188.4 & 164.8 & 1061.5 \\
\hline \multicolumn{4}{|c|}{ Average Demands } \\
\hline \multicolumn{3}{|c|}{ Thermal Demands } & \multirow{2}{*}{$\begin{array}{l}\text { Electrical Demand } \\
(\mathbf{k W})\end{array}$} \\
\hline $\begin{array}{l}\text { Cooling } \\
\text { (Ton) }\end{array}$ & \begin{tabular}{|l|}
$\begin{array}{l}\text { Heating } \\
\text { (kBtu/hr) }\end{array}$ \\
\end{tabular} & \begin{tabular}{|l|}
$\begin{array}{l}\text { DHW } \\
\text { (kBtu/hr) }\end{array}$ \\
\end{tabular} & \\
\hline 608 & 149.9 & 35.9 & 549.8 \\
\hline
\end{tabular}

After solving the optimization problem associated with this design configuration, MasterPlanner calculated the optimal equipment capacities as shown in Table 2 for the distributed as well as centralized systems (with and 
without TES). The capacities indicated for the distributed system are the sum of the capacities for all the building-level equipment. The results show a $\sim 30 \%$ reduction in the capacities of the electric chiller (EC) and air-sourced heat pump (ASHP) after chilled-water TES is added to the system.

Table 2. Optimal capacity of equipment for the case study

\begin{tabular}{|c|c|c|c|c|c|c|c|}
\hline Scenario & $\begin{array}{c}\text { Chilled } \\
\text { Water } \\
\text { Storage } \\
(\text { Ton-hr) }\end{array}$ & $\begin{array}{c}\text { HR } \\
\text { Chiller } \\
\text { (Ton) }\end{array}$ & $\begin{array}{c}\text { Electric } \\
\text { Chiller } \\
\text { (Ton) }\end{array}$ & $\begin{array}{c}\text { Boiler } \\
(\mathrm{kBtu} / \mathrm{hr})\end{array}$ & $\begin{array}{c}\text { DHW } \\
\text { Boiler } \\
(\mathrm{kBtu} / \mathrm{hr})\end{array}$ & $\begin{array}{c}\text { Electric } \\
\text { Heater } \\
(\mathrm{kBtu} / \mathrm{hr})\end{array}$ & $\begin{array}{c}\text { ASHP } \\
(\mathrm{kBtu} / \mathrm{hr})\end{array}$ \\
\hline Distributed & - & - & 1235.8 & 4199.9 & 157 & 90.7 & - \\
\hline $\begin{array}{c}\text { All-Electric } \\
\text { Central } \\
\text { Utility Plant }\end{array}$ & - & 142.8 & 1250.8 & - & - & - & 2305.7 \\
\hline $\begin{array}{c}\text { All-Electric } \\
\text { Central } \\
\text { Utility Plant } \\
+ \text { TES) }\end{array}$ & 5218.1 & 196.1 & 887.2 & - & - & - & 1601.9 \\
\hline
\end{tabular}

Figure 6 shows the resulting energy use intensity (EUI), life-cycle operational carbon emissions, and life-cycle equipment costs for the development for the distributed and centralized supply systems. Despite the sizable impact of TES on the capacities of EC and ASHP, the changes in the performance metrics resulting from this addition are negligible. Instead, most of the savings in emissions, cost, and EUI have resulted from optimizing the operation strategy of the cooling and heating equipment compared to the distributed system. Further, the significantly smaller values of the heating load compared to the cooling load (Table 1) have resulted in a small capacity for the heat-recovery chiller (HRC) which is less than $12 \%$ of the peak cooling demand (Table 2). This fact has prevented HRC from having a more tangible impact on saving cost and emissions.

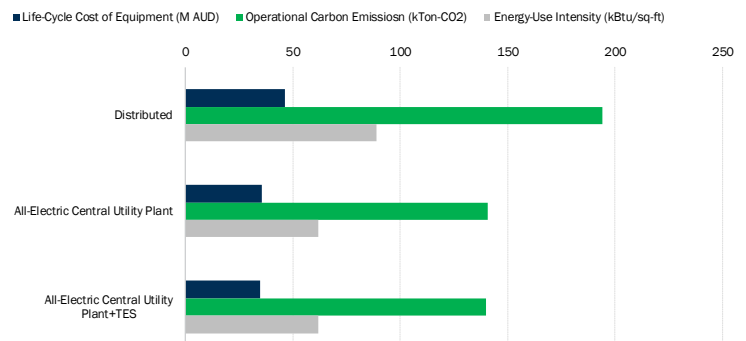

Figure 6. Life-cycle metrics associated with the three design scenarios of case study

Table 3 summarizes the percent improvements in performance metric of the central plant options over the distributed systems. The savings range from $23 \%$ to $31 \%$ compared to the baseline, i.e. the distributed system.
Table 3. Comparison between the performance metrics of the main configurations considered for the case study

\begin{tabular}{|c|c|c|c|}
\hline & $\begin{array}{c}\text { Life } \\
\text { Cycle } \\
\text { Cost }\end{array}$ & $\begin{array}{c}\text { Carbon } \\
\text { Emission }\end{array}$ & $\begin{array}{c}\text { Energy Use } \\
\text { Intensity } \\
\left(\mathrm{Kbtu} / \mathrm{ft}^{2}\right)\end{array}$ \\
\hline $\begin{array}{c}\text { Reductions (central vs } \\
\text { distributed) }\end{array}$ & $23 \%$ & $27 \%$ & $31 \%$ \\
\hline $\begin{array}{c}\text { Reductions (central+TES } \\
\text { vs distributed) }\end{array}$ & $25 \%$ & $30 \%$ & $31 \%$ \\
\hline
\end{tabular}

\section{CONCLUSIONS AND FUTURE WORK}

This paper presents a web-based tool for designing optimal central plants. This tool can help the design teams, (i) quickly conduct a central plant feasibility study, (ii) evaluate different central plant strategies, and (iii) optimize the design for first cost, operating cost, life cycle cost, energy use, or carbon impacts using hourly marginal carbon emissions of the grid. A case study on a new campus in Australia shows the useful insights provided by this tool on the optimal configurations, capacities, and hour-by-hour operation of the central thermal facilities as well as the sustainability gains obtained by following these insights when designing a central utility plant.

As powerful as the current version of the tool is, there are features that can be added to the tool in the future, including but not limited to

- Adding electricity generation to the supply technologies, including CHP engines and PV panels

- Adding battery storage to the energy storage systems

- $\quad$ Adding more types of heat pumps

- Using more complex models for simulating hourly performance of the equipment

- Adding geothermal systems to the supply equipment.

The tool introduced in this paper can also be integrated with the available master-planning tools, such as ReOpt, to take advantage of the capabilities of existing tools, and to create a platform with a more holistic approach toward designing optimal building and district-level energy systems.

\section{ACKNOWLEDGEMENTS}

The authors would like to thank Atelier Ten USA for the opportunity provided for developing this software and for the financial support for this work. Sepecial thanks to Allan Daly and Jagan Pilai of the Atelier Ten team for their significant contributions to the development of the tool and for their valuable inputs and feedback. 


\section{APPENDIX}

Figure 7 shows part of the results as viewed in MasterPlanner depicting the temperature analysis over the entire year.

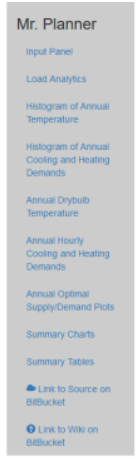

Weather Conditions and Load Characteristics

[Download Weather+Grid+Aggregate Demand Data]

Histogram of Annual Temperature [Download Image]

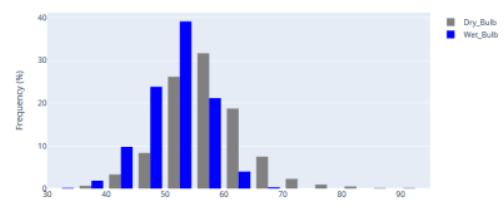

Figure 7. Screenshot from part of the weather analysis from MasterPlanner

\section{REFERENCES}

Atelier Ten. n.d. "Project Reports." atelierten.com/. Ball, Allison, Justin Billing, Caitlin Mccluskey, Pam Pham, Owen Pittman, Sean Lawson, Shamim Ahmad, Andrew Starr, Jonathon Rousseau, and Nicholas Lambert. 2018. "Australian Energy Update."

Best, Robert E., P. Rezazadeh Kalehbasti, and Michael D. Lepech. 2019. "A Novel Approach to District Heating and Cooling Network Design Based on Life Cycle Cost Optimization.” Energy 194 (March): 116837. https://doi.org/10.1016/j.energy.2019.116837.

Blair, Nate, Aron P Dobos, Janine Freeman, Ty Neises, Michael Wagner, Tom Ferguson, Paul Gilman, and Steven Janzou. 2014. "System Advisor Model, Sam 2014.1. 14: General Description." National Renewable Energy Lab.(NREL), Golden, CO (United States).

Build.com. n.d. "Cadet CSC101TW White 3415 BTU 120 Volt 1000 Watt Fan-Forced In-Wall Fan Heater from the Com-Pak Series." Accessed December 20, 2019.

https://www.build.com/cadetcsc101t/s460910?uid=1820301.

Deru, Michael, Kristin Field, Daniel Studer, Kyle Benne, Brent Griffith, Paul Torcellini, Bing Liu, Mark Halverson, Dave Winiarski, and Michael Rosenberg. 2011. "US Department of Energy Commercial Reference Building Models of the National Building Stock."

DiStefano, Kristen, and Henry Richardson. 2019. "The Future of Carbon Neutral Design: A Carbon Methodology for the Built Environment."
Dobos, Aron P. 2014. "PVWatts Version 5 Manual." National Renewable Energy Lab.(NREL), Golden, CO (United States).

EPA. 2016. "SOCIAL COST OF CARBON." https://www.whitehouse.gov/omb/oira/socialcost-of-carbon.

Grinberg, Miguel. 2018. Flask Web Development: Developing Web Applications with Python. " O'Reilly Media, Inc."

Hart, William E, Carl D Laird, Jean-Paul Watson, David L Woodruff, Gabriel A Hackebeil, Bethany L Nicholson, and John D Siirola. 2017. Pyomo-Optimization Modeling in Python. Vol. 67. Springer.

HomeAdvisor. n.d. "2019 Heat Pump Prices | Installation \& Replacement Costs HomeAdvisor.” Accessed December 20, 2019. https://www.homeadvisor.com/cost/heating-andcooling/install-a-heat-pump/.

Jacana Energy. 2019. "Jacana Energy Electricity Prices for the Northern Territory." Jacana Energy. 2019.

McKinney, Wes. 2011. "Pandas: A Foundational Python Library for Data Analysis and Statistics." Python for High Performance and Scientific Computing 14 (9).

Rezaie, Behnaz, and Marc A Rosen. 2012. "District Heating and Cooling: Review of Technology and Potential Enhancements." Applied Energy 93: 210.

Rossum, Guido Van. 2007. "Python Programming Language." In USENIX Annual Technical Conference, 41:36.

Sievert, Carson, Chris Parmer, Toby Hocking, Scott Chamberlain, Karthik Ram, Marianne Corvellec, and Pedro Despouy. 2017. "Plotly: Create Interactive Web Graphics via 'Plotly. Js." $R$ Package Version 4 (1): 110.

Siler-Evans, Kyle, Ines Lima Azevedo, and M Granger Morgan. 2012. "Marginal Emissions Factors for the US Electricity System." Environmental Science \& Technology 46 (9): 4742-48.

Simpkins, T, D Cutler, K Anderson, D Olis, E Elgqvist, M Callahan, and A Walker. 2014. "REopt: A Platform for Energy System Integration and Optimization." In ASME 2014 8th International Conference on Energy Sustainability Collocated with the ASME 2014 12th International Conference on Fuel Cell Science, Engineering and Technology. American Society of Mechanical Engineers Digital Collection.

Sioshansi, Ramteen, and Paul Denholm. 2010. "The Value of Concentrating Solar Power and Thermal Energy Storage." IEEE Transactions on Sustainable Energy 1 (3): 173-83. 
Snoek, Chris, Libing Yang, Tom Onno, Svend

Frederiksen, and Hans Korsman. 2002.

"Optimization of District Heating Systems by

Maximizing Building Heating System

Temperature Differences.” IEA District Heating

and Cooling Report $S 2$.

Tehrani, S Saeed Mostafavi, Robert A Taylor, Karthik Nithyanandam, and Ardalan Shafiei Ghazani. 2017. "Annual Comparative Performance and Cost Analysis of High Temperature, Sensible Thermal Energy Storage Systems Integrated with a Concentrated Solar Power Plant." Solar Energy 153: 153-72.

The Home Depot. n.d. "Noritz Indoor Residential Condensing Natural Gas Combination Boiler 180,000 BTUH-CB180-DV-NG - The Home Depot." Accessed December 20, 2019. https://www.homedepot.com/p/Noritz-IndoorResidential-Condensing-Natural-GasCombination-Boiler-180-000-BTUH-CB180-DVNG/300315643.

Tol, Richard S J. 2008. "The Social Cost of Carbon: Python programming language (Van Rossum 2007)Trends, Outliers and Catastrophes."

Economics: The Open-Access, Open-Assessment E-Journal 2.

US EIA. n.d. "EIA API." Accessed December 20, 2019. http://api.eia.gov/.

- 2018. "Delaware - State Energy Profile Overview - U.S. Energy Information Administration (EIA)." 2018. https://www.eia.gov/state/?sid=DE.

US EPA. 2018. "Emission Factors for Greenhouse Gas Inventories." https://www.ecfr.gov/cgi-bin/textidx?SID=ae265d7d6f98ec86fcd8640b9793a3f6\& $\mathrm{mc}=$ true $\&$ node $=\mathrm{pt} 40.23 .98 \& \operatorname{rgn}=\operatorname{div} 5 \#$ ap40.23.9 8_19.1.

USGBC. 2010. "Treatment of District or Campus Thermal Energy in LEED V2 and LEED 2009Design \& Construction."

"Weather Data by Location | EnergyPlus." 2019. EnergyPlus. 2019. https://energyplus.net/weatherlocation/southwest_pacific_wmo_region_5/AUS/ /AUS_NT.Darwin.Airport.941200_RMY. 